\title{
Principles of Somatic Movement Education for Architectural Design
}

\author{
Wiktor Skrzypczak
}

\begin{abstract}
An architect trying to predict the spatial effect of their design on its inhabitants often faces a dilemma. Their professional experience and personal feeling allows them to intuit its effect. Such intuition, however, might lack legitimacy in the dominant design practice. For over a century, the question of the felt space in architecture has been a topic of theoretical discussion, which led to the insight that the answer might lay not so much in studying the architectural structures, but rather in studying the bodies that inhabit them. And still the dominant architectural practice follows the outdated dualistic (mis-)understanding of the felt space. Another historical development took place in dance. Here, since the 1960s, the traditionally formalistic and objectifying understanding of dance has been strongly influenced by techniques of bodily sensitization, stemming from the field of somatics. In themselves rather diverse, these techniques have been institutionally delineated through the principles of somatic movement education. One of their characteristics is that somatic techniques are constantly re-emerging - not from a priori knowledge but from the study of one's own body and its interactions with the environment. This article envisages how such principles might be applied to architectural design practice and give rise to new embodied design practices - which might foster architects' sensory expertise and thus legitimize the felt knowledge in professional contexts.
\end{abstract}

Keywords: Empathy Theory; Phenomenology; Somatics; Practice; Sensory Expertise.

As a practicing architect, while designing, I often ask myself: What would it feel like to be in that space? Apparently a simple question, which entails however further questions - »Is it more about the feeling of being, or rather the feeling of the space itself? « In the tradition of the Enlightenment, questions of being were reduced to questions of thinking, the questions of the mind - the Cartesian »I think therefore I am«. In the same tradition, the architecture was not addressed as space at all, but rather as materials, forms, ornaments, and symbols (Friedrich/Gleiter 2007: 8) - as the merely "apparent elements of architecture« (Pallasmaa 2009: 145). If we try to answer the question 
of the feeling of being in the space from the rational perspective of the Enlightenment, we would have to deal with an allegedly autonomous, disembodied mind on one hand and lifeless architectural forms on the other - and with the yawning gap between them. For how could a meaning communicated between the mind and the matter? How could the architectural matter communicate with the mind without being reduced to signs and representations of something else than it is in itself? What is there to be found between the mind and the matter, which could help to overcome their strict distinction?

This article briefly sketches the historical developments in architectural theory, which proposed some methods of answering the question: How would it feel to be in that space? and which identified the body as the place where the answers might hide. It will become apparent that we still face a knowledge gap in architectural theory because we lack pragmatic methods of studying the body and applying bodily knowledge in design practice. Despite a robust philosophical framework, we are missing the practical methodology. What then, could be the principles of a bodily inquiry within architectural practice? One answer could be found among the principles of somatic movement education - which this article focuses on.

\section{Psychophysics, Empathy Theory, and Phenomenology}

How has the body, the missing link between mind and matter, been studied in the past? Briefly, since the mid-19th century, psychophysics studied the sensory organs and the nervous system, inextricably linking the stimuli with percepts. Soon after, Empathy Aesthetics absorbed these insights and attempted to explain our ability to perceive the expression of architecture with the ability to feel our own bodies. Moreover, it reduced the gap between the mind and the matter by placing the body within architectural space, instead of in front of the architectural object. Then, Husserl's phenomenology, although initially studying the consciousness and not explicitly the body, recognized the pre-logical ways of knowing and thus allowed for more adequate addressing of the bodily knowledge and of the role of the bodily movement in the constitution of perceptions. Merleau-Ponty's phenomenology then studied the body as a feeling body, as a center of our being-toward-the-world. His idea that there is no being without the world has given the word its own agency, and again reduced the gap by demonstrating that the human is one agent among many. This very brief sketch 
shows that the lineage of embodiment research in architectural theory has a rhythm of zooming out, drawing from empirical research and zooming in, immersing in experiential study, and each time closing the Cartesian gap a little bit: Psychophysics linked the stimulus with the percept, the Empathy Theory linked the architectural expression with bodily impression, and phenomenology linked logical knowing with bodily knowing and being with the world. How somatics, which is an approach in movement education, closes the gap between the mind and body is addressed in the following section.

\section{Somatics}

What would it feel like to be in that space? Now we know that we have to question the body itself in order to arrive at a detailed and tangible answer. The problem is that as much as the dominant Cartesian perspective distanced us from the felt qualities of the environment, it also distanced us from the felt reality of our bodies. This implies that if this predominant perspective shapes our design practice, our attitude to our own body might be shaped in this way too, at least in the professional, non-private context. In this moment the architect's body becomes relevant to their profession and the intimacy of the body therewith becomes an explicit component of the professional design process.

One of the fields in which professionals engage their whole bodily selves is dance. And also here, similarly to phenomenology in philosophy, postmodernism has changed the attitude toward the body. The rejection of form and embracing of improvisation, the rejection of the visual effect and embracing of the atmospheric affect, the rejection of the objective reception criteria and embracing of the intersubjective perception of meaning - these new values produced new dances and new aesthetics, which were closer to the audience and closer to the place of performance (cf. Novack 1990). In the 1970 s this new interest in the felt body strongly contributed to the popularization of somatic movement techniques in dance education. Somatics itself is a field of bodily movement practices, mostly developed throughout the 2oth century. It grounds itself in the notion of soma as a felt body that is aware of itself - a continuum of minding body and embodied mind as inseparable aspects of a human being (Skrzypczak 2018). The term somatics was coined in the 1970s by Thomas Hanna, a philosopher, movement practitioner, and movement theorist: 
»A soma is any individual embodiment of a [life] process, which endures and adapts through time, and it remains soma as long as it lives. The moment that it dies, it ceases to be a soma and becomes a body« (Hanna 1976: 31).

Hanna uses the Greek term soma to foreground the dynamic, evolutionary, self-determining processes - the sense of being alive. Soma, perceived from the first-person-perspective, is a phenomenon diametrically different from the objectified body perceived from the third-person-perspective (Hanna, in: Hanlon Johnson 2012: 371). The similarity to Merleau-Ponty's sensed body, $L e i b$, is self-evident. However, the main difference between phenomenology and somatics as disciplines can be grasped as the difference between an embodied mind and an enminded body. Both phenomenology and somatics can be understood as perceptual approaches which organize and systematize our interactions with the environment in the everyday life, however the dominant mode of inquiry in phenomenology is thinking, in somatics it is moving. Phenomenology uses thought experiments (such as phenomenological analysis), which might lead to new sensations and insights, whereas somatics, being a movement education approach, uses movement experiments which might also lead to new sensations and insights.

Historically, somatics evolved from numerous sources and diverged into three main »branches: somatic bodywork, somatic psychology, and somatic movement « (Eddy 2016: 8). As a field, it is highly decentralized and still growing while delivering new somatic methods and new applications, but also undertaking attempts at institutional self-definition and delineation. The following outline of somatic movement principles is based on the requirements for membership of the International Somatic Movement Education and Therapy Association (ISMETA) - which is an umbrella association publicly representing both somatic education organizations and individual somatic educators and practitioners.

Similarly to sport education in the general movement education curricula, somatic movement education is grounded in natural sciences and includes the principles of "movement observation and analysis; efficient alignment; spatial awareness; perceptual and motor development; neuromuscular, skeletal, tissue, and fluid awareness « (ISMETA 2017: 2-3, cf. also ISMETA 2003 in Eddy 2009). However, the core of somatic inquiry is the interrelations between the objective and subjective processes of the soma. In practical terms, somatic movement is guided through the observation of the interrelations between one's own »subjective processes" (ibid.: 1) of the 
psyche (primarily but not exclusively the processes of attention) and »objective processes" (ibid.: 1) of the physique.

Somatic movement is foremost a "pedagogical approach «(ibid.: 2 ). It can be understood as bodily literacy - it teaches the techniques of »reading « the body-mind and expressing it. By definition, it is learning through movement and touch (Eddy 2016). The particular contents and insights of such reading and expression vary strongly and depend on the particular case, the technique used, and how it was specifically applied. Yet, in general, somatic movement aims at finding »ease, support and pleasure (Eddy 2009: 6) in the experience of movement. It is a methodology of sensory sensitization which prioritizes the kinesthetic, tactile, and proprioceptive cues.

Somatic movement practitioners learn to recognize the »habitual patterns of perceptual, postural and movement interaction with [their] environment« (ISMETA 2017: 1). They learn that such habits cannot be attributed exclusively to the alleged »body« or »mind«, but instead are expressions of a specific somatic state. Practitioners also learn how to attain the new, nonhabitual possibilities of interaction. ${ }^{1}$ Another principle of somatic movement is releasing the practitioner's "movement inhibition and resistance" (ISMETA 2017: 2). Often, such patterns are experienced as muscular and mental tension. The release of such patterns is intended, because they often mask the internal proprioceptive sensations and narrow the perceived possibilities of action. These principles aim at both novel choices of interaction with the environment, but also at the "structural, functional, and expressive integration « (ISMETA 2017: 1) of the practitioner.

Somatic movement education is by definition non-authoritarian. Because many of its insights are phenomenological and pre-objective, the education consists of both learning from the teacher and constant rediscovery of the material by the student - learning from one's own knowing body. It demands that "teachers and students are co-active in the process of learning, discovering, and self-inquiry« (ISMETA 2017: 2) - students learn through guided exploration and learn how to guide their own explorations.

Because somatic movement education normally takes place in spaces shared by physically present participants, a large part of the communication

1 The non-habitual and novel choices are not explicitly included in ISMETA principles but have been emphasized by approaches such as critical somatics. Cf. Thomas Kampe (2015) »Eros and Inquiry: The Feldenkrais Method ${ }^{\circledR}$ as a Complex Resource $«$, in: Theatre, Dance and Performance Training, 6/2, 200-218, doi: 10.1080/19443927.2015.1027451. 
about what is happening within the practice is a non-verbal, direct, and inter-corporeal communication. However, somatic movement education usually offers specific verbal communication formats and teaches »communication and guidance through touch and verbal cues (ISMETA 2017: 1) which help to explicitly communicate the implicit observations. The higher purpose of somatic movement is often described as "homeostasis, co-regulation, and neuroplasticity« and "an embodied sense of vitality« (ISMETA 2017: 1).

This was a brief delineation of phenomenological traditions in architecture and movement education. They are systematic approaches pointing at the knowledge gaps which impede our understanding of the nature of interactions between the »subject « and the »world«, and between the »body" and »mind«. Architectural phenomenology and somatics are interested in understanding a specific kind of interactions, mainly, those which are pre-objective. Both approaches have been established as opposition, and then as extensions of objectifying knowledge traditions - Empathy Theory opposing the formal aesthetics, the phenomenology opposing the empiricist psychology, and somatics opposing the highly formalized and objectifying dance forms. Without pursuing a specific novel aesthetic both architectural phenomenology and somatics turn toward the aesthetics of everyday life and its direct, intuitive, and intimate character. Phenomenology and somatics try to transcend the habitual perceptions, the phenomenology turning toward the direct, present precepts, with somatics often turning to the evolutionary old, sensorimotor mechanisms.

\section{A Somatic Design Practice?}

The principles described above have a general character and admittedly lack the instructive precision which somatic movement techniques themselves have. But this general character allows for a deductive imagining, not of a somatic movement practice but a somatic design practice. The following are guidelines for a design practice that places the principles of the movement practice (emphasized in the text below) in the context of design practice. They are not based in any existing application of somatic movement for architectural design, although such attempts have been made (e.g. by Galen Cranz, Auxiliadora Gálvez, and Jader Tolja) they are much more of an aprioristic introduction to the theory of somatic design practice. Being a 
theory, the proposed principles remain general, but they also suggest some particular starting points:

- Take the ergonomics seriously. In terms of posture, do you prefer to be static or agile at your workplace? How do you physically prepare yourself for work? Do you have specific physical routines or rituals?

- Observe your psycho-physical states as you work on a design. Are there bodily states which support your design process? Do you prefer repose or arousal? Mind wandering or concentration? Find ways of facilitating these states.

- What media do you use in your design practice and how do they stimulate your sensory organs? Include mediums other than visual media in your design practice. How does the choice of medium affect your posture and movement? How does it limit what is thinkable and imaginable?

- As a private person - on a walk or on an excursion, observe your spatial behavior. Learn about your habitual interactions with the environment. How do you respond to narrow spaces? To wide spaces? To the crossing of boundaries? To voids above you and below you? To light and sound sources? To the presence of others? What other patterns of behavior do you notice?

- Keep moving. As you are learning about your perceptual, postural, and movement interactions with the environment keep moving, keep noticing the change, keep differentiating between the successive patterns and states.

- Think with your hands. Touch your environment, your design materials, and your media and tools attentively.

- Touch yourself attentively. Learn to feel what is underneath the skin surface, the internal space of your body. Observe how it resonates with the environment you are in. 
- Document your observations and share them with your peers. Be as specific as possible. Listen to your peers as they share their observations with you. Develop a vocabulary for the spatial and bodily phenomena that you experience. Find the intersubjective common ground of your perception processes but acknowledge the idiosyncrasies.

- In your explorations, notice the moments of spatial and bodily ease. Learn inducing this state through adequate movement facilitation and spatial design.

- In your explorations, notice the moments of spatial and bodily challenge. Learn to induce this state through adequate movement facilitation and spatial design. Make it stimulating and disruptive but be kind.

- Question your habitual interactions with the environment. Release your restriction patterns. Question your habitual design choices. Release what restricts your creative process.

- Interact with the environment non-habitually. Increase your range of spatial choices. Go for novel experiences and imaginations of space.

- Learn to empathize with the spatial behavior of the future inhabitants of your designs.

- Observe how the practice changes you. Cultivate the moments in which you experience a postural, functional, and expressive re-organization and integration.

- Study both natural and human sciences. Often, you will learn that your little private discoveries have already been made by others. Contextualize your felt knowledge. Be critical about what you know and how you know it.

To recap, this article argues that neither architectural practice nor dance practice is independent from the dominant philosophical worldview of the era. And while dance makers learned to make use of non-Cartesian movement techniques - to physically apply phenomenology and embodiment philosophy, architects often used phenomenology as a reflective, intellectual 
practice without explicitly studying their bodies and their role in the design process. It lead to the hypothesis that, as dancers learned to make less formal and more sensitively choreographed dances, architects might learn to cultivate their bodily selves in the design practice and thus answer the question: What would it feel like to be in that space? with a greater sensory expertise. Such cultivation of the body-mind could lead to the emergence of new somatic methods within the profession of architecture, because, as most somatic techniques are constantly re-emerging from actual movement practice, it is conceivable that a new somatic technique might emerge from design practice, if the designer approaches the practice not as a purely intellectual but as an embodied activity.

The remaining question then, is what difference might such embodied design practice make? Besides gaining expertise in questions about the sense of space, what effects on the architectural practice are thinkable? Sondra Frailegh, a dancer and philosopher, contrasted the objectifying knowledge with the subjectifying knowledge and characterized the first one as affecting the world through control, and the latter as affecting it through transformation (Fraleigh 1996). Thus, in order to comprehend the effects of somatic design practices we would have to find methods of observing and documenting such transformations, which can be expected to be more gradual and nuanced than those of objectifying knowledge. Accompanying research is necessary in order to identify the qualitative and quantitative differences between architecture imagined by a sensitive architect versus largely analytically generated architecture.

From a global vantage point, through the general critique of modernity, one effect, that almost has a political relevance, could be a shift in architects' value systems, or maybe a greater appreciation of the humanists among the engineers. Undoubtedly, fields such as somatics are value-driven communities, thus their place in supposedly value-free universities has to be questioned. However, somatic education might find its place in architectural education, because, as a pragmatic approach, it does not presuppose a philosophical indoctrination. To put it boldly, that is because its core values are not transcendental, but immanent. They emanate from attentive bodily practices. As architects, we are neither philosophers nor movers, but by learning to cultivate our bodily selves and training our senses, we might understand better how our designs affect their inhabitants and thus increase the quality of the built environment. 


\section{References}

Eddy, Martha (2009): »A Brief History of Somatic Practices and Dance: Historical Development of the Field of Somatic Education and its Relationship to Dance«, in: Journal of Dance and Somatic Practices 1/1, doi: 10.1386/jdsp.1.1.5/1

Eddy, Martha (2016): Mindful Movement: The Evolution of the Somatic Arts and Conscious Action, Chicago: University of Chicago Press.

Fraleigh, Sondra Horton (1996), »The Spiral Dance: Toward a Phenomenology of Somatics", in: Dance Faculty Publications 8. http://digitalcommons.brockport.edu/ dns_facpub/8, accessed July 15, 2021.

Friedrich, Thomas/ Cleiter, Jörg (2007): Einfühlung und phänomenologische Reduktion: Grundlagentexte zu Architektur, Design und Kunst (Empathy and Phenomenological Reduction: Foundational Texts on Architecture, Design, and Art). Berlin: Lit Verlag.

Hanna, Thomas (1976): »The Field Of Somatics «, in: Somatics: Magazine-Journal of the Bodily Arts and Sciences 1/1.

ISMETA (2017): Registered Somatic Movement Educator and Therapist Training Requirements, https://ismeta.org/ wp-content/uploads/2017/06/ISMETA_ Registered-Professional-MemberRequirements.pdf, accessed July 15, 2021.
Jacquet, Benoît (2012): »The State of Architectural Phenomenology«, in: Environmental \& Architectural Phenomenology 23/2.

Johnson, Don Hanlon/ Rytz, Thea/ Mauch, Christine, eds. (2012): Klassiker der Körperwahrnehmung. Erfahrungen und Methoden des Embodiment (Classics of Body Awareness. Experiences and Methods of Embodiment), Bern: Huber Verlag.

Novack, Synthia (1990): Sharing the Dance: Contact Improvisation and American Culture, Madison: University of Wisconsin Press.

Pallasmaa, Juhani (2009): The Thinking Hand: Existential and Embodied Wisdom in Architecture, Chichester: John Wiley \& Sons Ltd.

Robinson, Sarah/Pallasmaa, Juhani, eds. (2017): Mind in Architecture: Neuroscience, Embodiment, and the Future of Design, Cambridge, MA: The MIT Press.

Skrzypczak, Wiktor (2018): »Introduction to a Somatic Inquiry of Architectural Space«, in: Matthias Balestrem/Ignacio Borrego/Donatella Fioretti/Ralf Pasel/ Jürgen Weidinger, $C A^{2} R E$-Conference for Artistic and Architectural (Doctoral) Research, https://www.pep.tu-berlin.de/wp-content/ uploads/2020/11/ABSTRACTS-CA2REBERLIN.pdf, accessed October 5, 2021. 